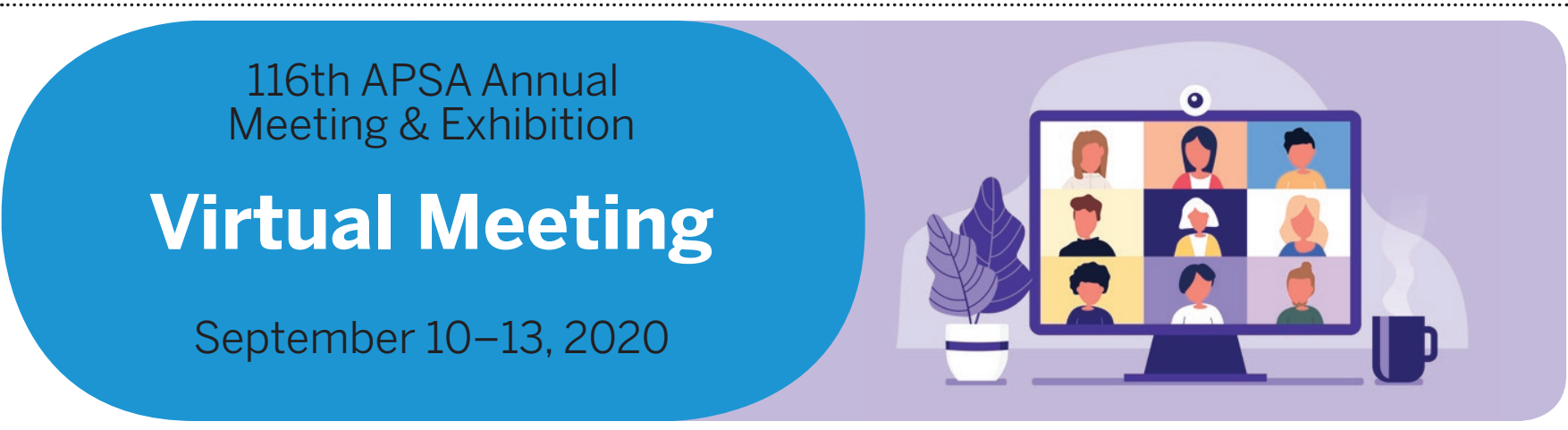

\title{
2020 APSA Annual Meeting \& Exhibition Transitioning to Virtual Format
}

T he safety of the American Political Science Association (APSA) community is our top priority. In light of the current situation surrounding COVID-19, we will deliver our 116th American Political Science Association's Annual Meeting \& Exhibition, scheduled for September 10-13, 2020 in San Francisco, as a virtual digital event. We very much look forward to bringing together the APSA community to learn and connect in this new virtual format.

The APSA Annual Meeting helps create a vibrant and sustainable community for attendees and the discipline. We recognize the essential role of the annual meeting is more important than ever, and the need to bring our scholarly community together, share the latest research and scholarship, provide opportunities for scholars to learn about the job market, and be able to network with colleagues in their areas of expertise.

Importantly, the virtual event will occur the same week as originally scheduled. The days and times will be confirmed later, but we will be using the current program time zone of Pacific time. We plan to keep most, if not all, of the program content, depending upon an individual's ability to participate. There will be virtual rooms for section business meetings, related group meetings, editorial board meetings, and committee meetings.

We will be asking everyone to reconfirm their participation in the program. We ask that participants, especially those in volunteer roles, think carefully about their time commitments to ensure they can provide quality feedback and a robust discussion in these important roles. As such, we will be opening another call for volunteer roles (chairs and discussants) shortly.

Further, at the request of the program chairs, there will be two additional calls for proposals based on current events:

1. "Relevance, Quality, and Expedience: Political Science Responds to COVID-19"

2. "Black Lives, Black Deaths, and Black Protest: Political Scientists Respond (Anew) to a Persistent Challenge."
The full call, along with a link for submission, will be sent out soon. Proposals will be reviewed by the program chairs.

We will be contacting all currently registered attendees soon to inquire if they would like their registration fees adjusted for the virtual event or refunded. We plan to issue a revised pricing schedule for registration fees for the virtual event very shortly.

We are very grateful for the tremendous work done by program chairs Efrén Pérez, UCLA, and Andra Gillespie, Emory University, our division chairs, and many other volunteers who make the annual meeting a reality. We are very excited and proud to deliver this important and innovative event to the APSA community. 